\title{
Characterization of Certain Proteinase Isoenzymes Produced by Benign and Virulent Strains of Bacteroides nodosus
}

\author{
By RICHARD S. GREEN \\ Wallaceville Animal Research Centre, Research Division, Ministry of Agriculture and Fisheries, \\ Private Bag, Upper Hutt, New Zealand
}

(Received 29 April 1985)

\begin{abstract}
Three proteinase isoenzymes from one benign strain of Bacteroides nodosus and five proteinase isoenzymes from each of two virulent strains of $\boldsymbol{B}$. nodosus were purified by horizontal slab polyacrylamide gel electrophoresis. The purified isoenzymes hydrolysed casein, collagen I, collagen III, elastin, $\alpha$-elastin, fibrinogen, gelatin, haemoglobin and $\alpha$-keratin. The $\mathrm{pH}$ optima of all the isoenzymes lay between 7.25 and 9.5 , the range of $8.75-9.25$ being common to all. The isoenzymes were inhibited by phenylmethylsulphonyl fluoride, diphenylcarbamyl chloride, L-(1tosylamide-2-phenyl)ethyl chloromethyl ketone, EGTA and EDTA, indicating that they were chymotrypsin-like serine proteinases that require a metal ion for stability or activity. EDTA inhibition was not reversed by addition of $\mathrm{Ca}^{2+}$ or $\mathrm{Mg}^{2+}$. Some isoenzymes were activated by $\mathrm{Mg}^{2+}, \mathrm{Ca}^{2+}, \mathrm{Cr}^{3+}$ and $\mathrm{Se}^{4+}$ and all were inhibited by $\mathrm{Fe}^{2+}, \mathrm{Co}^{2+}, \mathrm{Cu}^{2+}, \mathrm{Zn}^{2+}, \mathrm{Cd}^{2+}$ and $\mathrm{Hg}^{2+}$. Isoenzymes from benign strains had a lower temperature stability, losing all activity at $55^{\circ} \mathrm{C}$, whereas those from virulent strains lost all activity at $60^{\circ} \mathrm{C}$.
\end{abstract}

\section{INTRODUCTION}

Bacteroides nodosus, the principal agent of footrot in sheep, produces extracellular proteinases in vitro (Beveridge, 1941; Thomas, 1963), and it has been postulated that these enzymes have a role in the pathogenesis of the disease (Thomas, 1964). The possible association between the proteolytic activity of $B$. nodosus isolates and their virulence, although not verified directly, has aroused special interest with regard to the epidemiology of benign and virulent forms of $B$. nodosus infections in sheep (Egerton \& Parsonson, 1969) and other ruminants (Egerton \& Laing, 1978/1979).

Crude or partially purified preparations of $B$. nodosus proteinases are serine-type enzymes requiring a divalent metal ion for activity (Kortt et al., 1982). A limited range of substrates is attacked, including casein, elastin, fibrin and denatured haemoglobin (Broad \& Skerman, 1976). Although Thomas (1964) considered that the digestion of hoof particles incorporated in $B$. nodosus cultures indicated keratinolytic activity, enzyme preparations do not attack native keratin substrates in vitro (Broad \& Skerman, 1976; Kortt et al., 1982).

Extracellular proteinases of isolates from benign and virulent $B$. nodosus infections have quantitatively different activities on casein and elastin (Thomas, 1962; Egerton \& Parsonson, 1969; Stewart, 1979) as well as differing temperature stabilities at $37^{\circ} \mathrm{C}$ (Depiazzi \& Richards, 1979) and at $55^{\circ} \mathrm{C}$ (Kortt et al., 1982). These distinctive features of the isolates have served to differentiate the two principal clinical conditions with which they are associated (Richards $e t$ al., 1980), as has a qualitative method decribed by Every (1982) based on the characteristic isoenzyme patterns and molecular weights of the bacterial proteinases after polyacrylamide gel

Abbreviations: DPCC, diphenylcarbamyl chloride; PMSF, phenylmethylsulphonyl fluoride; TPCK, L-(l-tosylamide-2-phenyl)ethyl chloromethyl ketone. 
electrophoresis. As several of these isoenzymes appear to be specific to benign or virulent strains of $B$. nodosus, a method for their purification was developed (Every \& Green, 1982) and their principal properties are described here.

\section{METHODS}

Enzyme preparation. Bacteroides nodosus strains 65 and 91, isolated from clinical cases of ovine footrot in New Zealand, were used as the source of the virulent bacterial proteinase isoenzymes. Isoenzymes were also purified from strain 134 isolated from a case of benign footrot in Australia and obtained from the McMaster Laboratory, Division of Animal Health, CSIRO, Sydney, Australia.

The organisms were grown anaerobically at $37^{\circ} \mathrm{C}$ in liquid Trypticase/arginine/serine medium to maximum cell density $\left(1-3 \times 10^{8}\right.$ cells $\left.\mathrm{ml}^{-1}\right)$ as described by Skerman (1975). Bacteria were removed from the culture by centrifugation at $12000 \mathrm{~g}$ and the supernatant was concentrated 30-fold in an Amicon ultrafiltration unit with a PM 10 membrane. This concentrate containing the isoenzymes was stored at $4{ }^{\circ} \mathrm{C}$ and used within one week.

Individual proteinase isoenzymes were purified by horizontal slab polyacrylamide gel electrophoresis in a 9$17 \%$ gradient. The isoenzyme bands were detected by reaction with fluorescein-casein substrate as described by Every \& Green (1982). The isoenzymes from the benign strain (benign isoenzymes) were designated Obl, 5 and 6 and the isoenzymes from the virulent strains (virulent isoenzymes) were designated Ov1, 2, 4,6 and 7 as described by Every (1982). These were the only isoenzymes produced in significant quantities by the strains used. Isoenzyme Ov2 was obtained from virulent strain 91 . The purified isoenzymes were frozen rapidly with dry ice/ethanol, a sample being kept separate to determine the purity of the isolated proteinase isoenzymes by the quantitative proteolytic zymogram method of Every (1981). Individual isoenzymes from separate purifications were thawed, combined, divided into aliquots and refrozen with dry ice/ethanol.

Substrate preparation and substrate specificity. Collagen I was prepared from the Achilles tendon of Merino sheep by the method of Piez et al. (1963). Collagen III (reticulin) was prepared from the renal cortex of Merino sheep by the method of Pras \& Glynn (1973). Elastin and soluble $\alpha$-elastin were prepared from the ligamentum nuchae of Merino sheep by the method of Partridge et al. (1955). $\alpha$-Keratin was prepared from the skin of the inguinal pouch of Merino sheep by the method of Steinert et al. (1979).

The substrate specificity of the purified isoenzyme preparations was determined by the radial diffusion-in-gel method of Schumacher \& Schill (1972), with the modifications of Every \& Green (1982), except that the buffer used was $100 \mathrm{~mm}$-piperazine $/ \mathrm{NaCl} / \mathrm{HCl} \mathrm{pH} 9 \cdot 0$. The substrate concentrations were $0.75 \%(\mathrm{w} / \mathrm{v})$ casein, $0 \cdot 13 \%(\mathrm{w} / \mathrm{v})$ collagen I, $0 \cdot 15 \%(\mathrm{w} / \mathrm{v})$ collagen III, $0 \cdot 15 \%(\mathrm{w} / \mathrm{v})$ elastin, $0.5 \%(\mathrm{w} / \mathrm{v}) \alpha$-elastin, $0 \cdot 15 \%(\mathrm{w} / \mathrm{v})$ fibrinogen, $0.5 \%(\mathrm{w} / \mathrm{v})$ gelatin, $0 \cdot 15 \%(w / v)$ haemoglobin and $0 \cdot 15 \%(w / v) \alpha$-keratin. All results are the mean of two to four assays.

Pronase was used to prepare the standard curves in which one pronase unit was equivalent to one $B$. nodosus proteinase unit (one pronase unit will liberate amino acids from casein equivalent in Folin colour to 1.0 mequiv. tyrosine in $1 \mathrm{~min}$ at $\mathrm{pH} 7.4$ and $40^{\circ} \mathrm{C}$ ).

Hide powder azure assay. The method of Rinderknecht et al. (1968) was modified by using $100 \mathrm{~mm}-$ piperazine $/ \mathrm{NaCl} / \mathrm{HCl}$ buffer $\mathrm{pH} 9 \cdot 0$, and reducing the assay volume to $1.2 \mathrm{ml}$ and the amount of hide powder azure to $6 \mathrm{mg}$ per assay. The reaction was terminated by filtration through a $0.22 \mu \mathrm{m}$ membrane filter (Sartorius) before reading on the spectrophotometer at $595 \mathrm{~nm}$. All results are the mean or two to four assays.

Protein determination. Protein was measured by the fluorometric assay of Böhlen et al. (1973) with samples prepared as described by Every \& Green (1982).

pH optima and pH stability. pH optima were determined by the hide powder azure assay with the buffer systems piperazine, piperazine $/ \mathrm{NaCl}$ and glycine $/ \mathrm{NaCl}$ (all at $100 \mathrm{mM}$ ) and titrated with $\mathrm{HCl}$ or $\mathrm{NaOH}$ to the final $\mathrm{pH}$ of $5-12$.

For the pH stability studies, an additional buffer system was used with potassium hydrogen phthalate/ $\mathrm{NaOH}$ at $100 \mathrm{~mm}$ to extend the range to $\mathrm{pH} 4 \cdot 0$. Each proteinase preparation was incubated in the various buffers in the $\mathrm{pH}$ range 4- 12 for $120 \mathrm{~min}$ at $37^{\circ} \mathrm{C}$. The isoenzymes were then titrated to $\mathrm{pH} 9.0$ with $0.05 \mathrm{M}-\mathrm{HCl}$ or $0.05 \mathrm{M}-\mathrm{NaOH}$ and their proteinase activities determined by the hide powder azure assay.

Thermal stability. Each isoenzyme was heated for $20 \mathrm{~min}$ at specified temperatures within the range $35-65^{\circ} \mathrm{C}$ and proteinase activity was determined at $37^{\circ} \mathrm{C}$ by the hide powder azure assay.

Effect of inhibitors. The effect of inhibitors was determined using $\varepsilon$-aminocaproic acid, iodoacetamide, phenanthroline, EGTA, EDTA, PMSF (phenylmethylsulphonyl fluoride), soyabean trypsin inhibitor, ovomucoid trypsin inhibitor, TPCK [L-(1-tosylamide-2-phenyl)ethyl chloromethyl ketone] and DPCC (diphenylcarbamyl chloride). The isoenzyme preparations were pre-incubated with the inhibitors at concentrations given in Results for $30 \mathrm{~min}$ at $37^{\circ} \mathrm{C}$ and the proteinase activity determined by the hide powder azure assay.

Effect of metal ions. Various metal ions at $1 \mathrm{mM}$ final concentration were added to the hide powder azure assay mixtures immediately before incubation. 
Source of chemicals. Fibrinogen, pronase and hide powder azure were obtained from Calbiochem. Haemoglobin, piperazine, $\varepsilon$-aminocaproic acid, phenanthroline, EGTA, PMSF, TPCK, soyabean trypsin inhibitor and ovomucoid trypsin inhibitor were obtained from Sigma. Casein (Hammarsten), EDTA, iodoacetamide, sodium selenite and all the metals as either their chloride, nitrate or sulphate were obtained from BDH. Gelatin was obtained from Difco and DPCC was obtained from Hopkin \& Williams.

Statistics. For comparing data for the various isoenzymes on substrate specificity, effects of inhibitors and effects of metal ions, results were subjected to the Friedmann two way analysis by ranks test (Conover, 1980). Results for $\mathrm{pH}$ optima, pH stability and thermal stability were analysed using the Genstat analysis of variance and the minimum significant differences were determined. The Genstat is a general statistical program developed at Rothamsted Experimental Station, Harpenden, UK, and it was run on a Prime 750 computer.

\section{RESULTS AND DISCUSSION}

pH optima. These are indicated in Fig. 1. In the piperazine/piperazine- $\mathrm{NaCl} / \mathrm{glycine}-\mathrm{NaCl}$ buffer system, the benign isoenzymes Obl, Ob5 and Ob6 had pH optima ranges of 8.5-9.25, $7 \cdot 75-9.25$ and $8 \cdot 5-9 \cdot 5$, respectively. $\mathrm{pH}$ optima ranges for the virulent isoenzymes Ov1, Ov2, Ov4, Ov6 and Ov7 were $8 \cdot 75-9 \cdot 5,7 \cdot 25-9 \cdot 5,7 \cdot 75-9 \cdot 25,7 \cdot 5-9 \cdot 25$ and $8 \cdot 25-9 \cdot 25$, respectively. All isoenzymes had an optimal range of $\mathrm{pH} 8.75$ to 9.25 in common.

Substrate specificity. The activities of the various isoenzymes on soluble and insoluble natural substrates are shown in Table 1. In addition to these substrates found to be susceptible to $B$. nodosus proteinases by previous authors (see Introduction) the purified isoenzymes also hydrolysed collagen I, collagen III and $\alpha$-keratin. In previous studies (Broad \& Skerman, 1976; Kortt et al., 1982) a hard keratin (wool) was used as a substrate, whereas the present observations were made on a soft keratin isolated from the stratum corneum, an epidermal component more allied to the site of $B$. nodosus infection. The soluble substrates fibrinogen, $\alpha-$ elastin, casein and gelatin were most readily hydrolysed, followed by collagen III, $\alpha$-keratin and haemoglobin. Due to low enzyme concentrations, elastin and collagen I were not completely hydrolysed and therefore an accurate estimate of the rate of hydrolysis was not possible, although collagen I was apparently hydrolysed more rapidly than elastin.

When all the substrates tested were taken into account, the virulent isoenzyme Ov2, unique to strain 91 , was generally the most active followed by Ov4 $>$ Ov1 $\simeq$ Ov $7 \simeq$ Ob1 $\simeq$ Ob6 $>$ Ob5 > Ov6; the virulent isoenzymes generally were more actively proteolytic than the benign isoenzymes.

pH stability. Some differences in the patterns of $\mathrm{pH}$ stability of isoenzymes from benign and virulent strains were evident (Fig. 2). The benign isoenzymes $\mathrm{Obl}$ and $\mathrm{Ob5}$ were stable throughout $\mathrm{pH}$ ranges $8 \cdot 0-10 \cdot 0$ and $8 \cdot 0-10 \cdot 5$, respectively. The benign isoenzyme Ob6 was unstable under the assay conditions. The virulent isoenzymes Ov1, Ov2, Ov4, Ov6 and Ov7 were stable at $\mathrm{pH}$ ranges of $7 \cdot 0-10 \cdot 0,6 \cdot 5-9 \cdot 5,6 \cdot 5-10 \cdot 0,6 \cdot 5-10 \cdot 0$ and $9 \cdot 0-10 \cdot 5$, respectively.

Thermal stability. The benign and virulent isoenzymes were stable for $20 \mathrm{~min}$ at $40^{\circ} \mathrm{C}$, but lost about $20 \%$ of their activities at $45^{\circ} \mathrm{C}$. At $50{ }^{\circ} \mathrm{C}$, Ov1, Ov2 and Ov4 lost approximately $30 \%$ of their activity and Ov6, Ov7, Obl, Ob5 and Ob6 lost approximately $60 \%$. At $55^{\circ} \mathrm{C}$, Ov6 and Ov7 had only half the remaining activity of Ov1, Ov2 and Ov4 with $13.5 \%$ and $27 \%$ remaining respectively. The benign isoenzymes had no activity after $20 \mathrm{~min}$ at $55^{\circ} \mathrm{C}$ and the virulent isoenzymes had no remaining activity after $20 \mathrm{~min}$ at $60^{\circ} \mathrm{C}$. The differences between percentage readings for the assays of each isoenzyme at the stated temperatures were significant $(P<0.01)$. This distinction between benign and virulent isolates applied to both Australian and New Zealand strains as reported by Green (1984) for unpurified proteinases. However, it is in contrast to the findings for enzyme preparations from strain 92 studied by Thomas (1964) and the strains studied by Kortt et al. (1982), all of which were reported to be stable up to $70^{\circ} \mathrm{C}$.

Effects of inhibitors. PMSF (1 mM) caused an average inhibition of 90\% (70-100\%) for the benign and virulent isoenzymes, while at $0.1 \mathrm{mM}$ inhibition averaged $30 \%(0-81 \%) ; \mathrm{Ob} 5$ and Ob6 were not inhibited at this concentration. TPCK ( $1 \mathrm{mM})$ caused $50 \%$ inhibition $(30-60 \%)$ for all isoenzymes with $0 \cdot 1 \mathrm{mM}$ causing $22 \%$ inhibition $(0-37 \%)$ except for Ob6. DPCC caused 


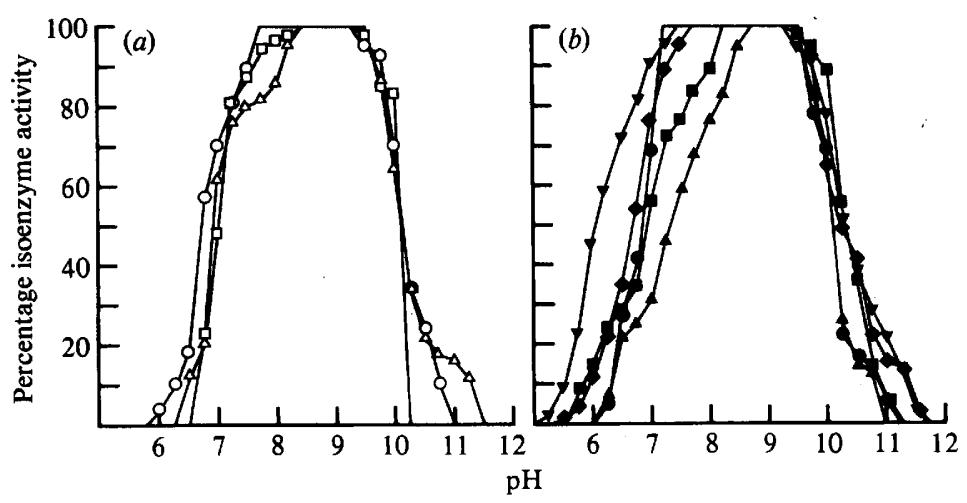

Fig. 1. pH optima of proteinase isoenzymes from $(a)$ benign and $(b)$ virulent $B$. nodosus. The $\mathrm{pH}$ of the isoenzymes was adjusted to that required (between 5.0 and $12 \cdot 0$ ) with the buffers and then proteinase activity was determined by the hide powder azure assay. $\square$, Obl ; O, Ob5; $\triangle$, Ob6; $\Delta$, Ov1; O, Ov2; $\diamond$, Ov4; , Ov6; $\square$, Ov7. The $100 \%$ value for each isoenzyme activity was a change in the absorbance of $0 \cdot 2,0 \cdot 25,0 \cdot 16,0 \cdot 2,0 \cdot 16,0 \cdot 16,0 \cdot 33$ and $0 \cdot 18$ per hour respectively. Differences between percentage readings for assays of each isoenzyme at stated $\mathrm{pH}$ values were significant $(P<0.05)$.

\section{Table 1. Substrate specificity of proteinase isoenzymes from virulent and benign $B$. nodosus}

The substrate specificity was determined by the radial diffusion-in-gel method. The rate of substrate hydrolysis was compared with pronase.

\begin{tabular}{|c|c|c|c|c|c|c|c|c|c|}
\hline \multirow[b]{2}{*}{ Substrate } & \multirow{2}{*}{$\begin{array}{c}\text { Substrate } \\
\text { concn } \\
(\%, w / v)\end{array}$} & \multicolumn{8}{|c|}{ Activity of isoenzymes* } \\
\hline & & Ovl & Ov2 & Ov4 & Ov6 & Ov7 & Obl & Ob5 & Ob6 \\
\hline Casein & 0.75 & 474 & 4800 & 791 & 37 & 289 & 166 & 58 & 194 \\
\hline Collagen I & 0.13 & $<20$ & $<20$ & $<20$ & $<20$ & $<20$ & $<20$ & $<20$ & $<20$ \\
\hline Collagen III & $0 \cdot 15$ & 27 & 246 & 224 & 6 & 40 & 22 & 21 & 35 \\
\hline Elastin & 0.15 & $\mathrm{tr}$ & $\operatorname{tr}$ & $\operatorname{tr}$ & $\operatorname{tr}$ & $\operatorname{tr}$ & tr & $\operatorname{tr}$ & $\operatorname{tr}$ \\
\hline$\alpha$-Elastin & 0.5 & 154 & 2339 & 699 & 24 & 216 & 264 & 111 & 252 \\
\hline Fibrinogen & 0.15 & 466 & 4246 & 5446 & 161 & 943 & 231 & 278 & 604 \\
\hline Gelatin & 0.5 & 174 & 2154 & 1025 & 24 & 162 & 252 & 84 & 230 \\
\hline Haemoglobin & $0 \cdot 15$ & 5 & 36 & 20 & 0.7 & 4 & 10 & 11 & 13 \\
\hline$\alpha$-Keratin & 0.15 & 11 & 86 & 93 & 3 & 30 & 7 & 7 & 14 \\
\hline
\end{tabular}

tr, Trace.

* All values are expressed as pronase units per $\mu \mathrm{g}$ isoenzyme protein. Results for different isoenzymes acting on the same substrate, and for the same isoenzyme acting on different substrates were all significantly different at the $1 \%$ level.

$100 \%$ inhibition at $1 \mathrm{mM}, 94 \%(75-100 \%)$ inhibition at $0.1 \mathrm{~mm}$ and $33 \%(0-63 \%)$ inhibition at $0.01 \mathrm{mM}$ for all isoenzymes except Ov7. EDTA ( $1 \mathrm{mM}$ ) caused $100 \%$ inhibition, $0 \cdot 1 \mathrm{mM}$-EDTA caused $77 \%$ inhibition $(37-100 \%)$ and $9 \%$ inhibition (0-19\%) was caused by 0.01 mM-EDTA; $\mathrm{Ob} 1$ and Ob6 were not inhibited at this concentration. After EDTA inhibition ( $1 \mathrm{mM}$ ), isoenzyme activity was not restored by the addition of either $5 \mathrm{mM}-\mathrm{Ca}^{2+}$ or $5 \mathrm{mM}-\mathrm{Mg}^{2+}$. EGTA ( $1 \mathrm{mM})$ caused $100 \%$ inhibition, $0.1 \mathrm{mM}$-EGTA caused $78 \%$ inhibition $(52-100 \%)$ and $27 \%(0$ $100 \%$ ) inhibition was caused by $0.01 \mathrm{mM}-\mathrm{EGTA}$; Ov 7 and Ob5 were totally inhibited and Ovl, Ov4, Obl and Ob6 were not inhibited. There was no inhibition by $1 \mathrm{mg} \mathrm{ml}^{-1}$ of soyabean or ovomucoid trypsin inhibitors, or by $1 \mathrm{~mm}$ concentrations of the thiol inhibitor iodoacetamide, the fibrinolytic inhibitor $\varepsilon$-aminocaproic acid or the heavy metal chelator phenanthroline. Inhibition of the different isoenzymes by the same inhibitor was not significantly different but the effect of different inhibitors on the same isoenzyme was significant at the $1 \%$ level. 


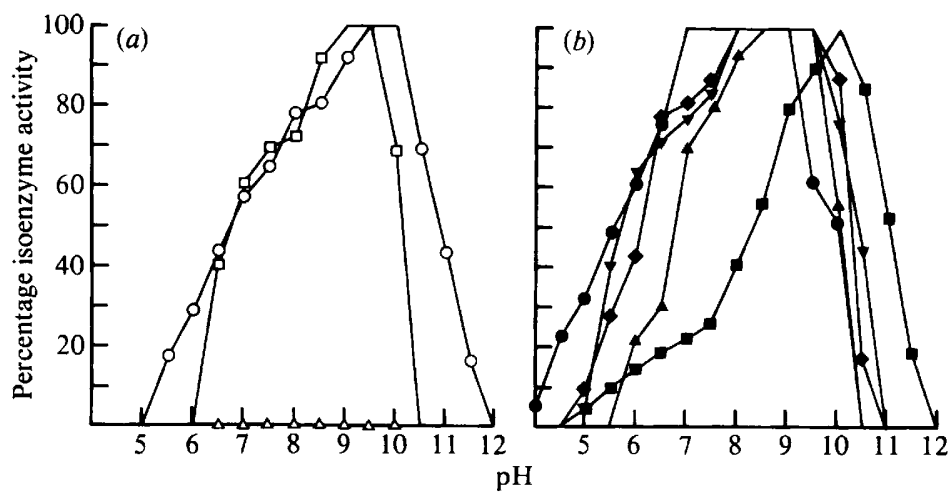

Fig. 2. $\mathrm{pH}$ stabilities of proteinase isoenzymes from $(a)$ benign and (b) virulent $B$. nodosus. Each isoenzyme preparation was incubated in the $\mathrm{pH}$ range $4.0-12.0$ for $120 \mathrm{~min}$ at $37^{\circ} \mathrm{C}$. The isoenzymes were titrated to $\mathrm{pH} 9.0$ with $0.05 \mathrm{M}-\mathrm{HCl}$ or $0.05 \mathrm{M}-\mathrm{NaOH}$ and their proteinase activities were determined by the hide powder azure assay. $\square$, Ob1; O, Ob5; $\triangle$, Ob6; $\Delta$, Ov1; , Ov2; $\bullet$, Ov4;, Ov6; , Ov7. The $100 \%$ value for each isoenzyme activity was a change in the absorbance of $0 \cdot 2,0 \cdot 15$, $0,0 \cdot 2,0 \cdot 16,0 \cdot 16,0.33$ and 0.21 per hour respectively. Differences between percentage readings for assays of each isoenzyme at stated $\mathrm{pH}$ values were significant $(P<0.05)$.

The inhibition of all the isoenzymes by PMSF confirms that they are serine proteinases, the inhibition by TPCK and DPCC further indicating that they are chymotrypsin-like enzymes. The inhibition by TPCK appears similar to that reported by Kortt et al. (1982), but the PMSF results differ. Direct comparison with the results of Kortt et al. (1982) is difficult because their 'purified' enzyme would have been a mixture of isoenzymes and neither the inhibition assay method nor the concentration of PMSF was described.

Effect of metal ions. For all the isoenzymes except $\mathrm{Ov} 4 \mathrm{Mg}^{2+}$ (mean for all isoenzymes $112 \%$; range $86-163 \%)$ and $\mathrm{Ca}^{2+}(121 \% ; 79-177 \%)$ were not inhibitory and $\mathrm{Sr}^{2+}(87 \% ; 40-104 \%)$ inhibited only Ov4 and Ov7. $\mathrm{Cr}^{3+}(90 \% ; 45-122 \%)$ inhibited Ov4, Ov6, Ov7 and Ob6, and $\mathrm{Mn}^{2+}(87 \% ; 58-110 \%)$ inhibited Ov4, Ov6 and Ov7. Se ${ }^{4+}(100 \% ; 52-134 \%)$ inhibited Ov2, Ov4 and $\mathrm{Ob} 6$, and $\mathrm{Pb}^{2+}(77 \% ; 34-106 \%)$ inhibited all except Ov1 and Ov2. All isoenzymes were inhibited by $\mathrm{Ni}^{2+}(53 \% ; 21-84 \%), \mathrm{Cu}^{2+}(28 \% ; 7-49 \%), \mathrm{Cd}^{2+}(14 \% ; 0-26 \%), \mathrm{Hg}^{2+}(27 \% ; 0$ $38 \%)$ and $\mathrm{Fe}^{2+}(17 \% ; 0-39 \%)$ with $\mathrm{Cd}^{2+}$ totally inhibiting $\mathrm{Ov} 1$ and $\mathrm{Ov} 4, \mathrm{Hg}^{2+}$ totally inhibiting Ov6 and $\mathrm{Fe}^{2+}$ totally inhibiting Ov1, Ov4, Ov6 and Ov7. $\mathrm{Co}^{2+}$ and $\mathrm{Zn}^{2+}$ totally inhibited all isoenzymes. Isoenzymes Ov1, Ov2, Ov7 and Ob5 were activated $(>10 \%$ increase above initial activity) by the addition of $\mathrm{Mg}^{2+}$; Ov1, Ov2 and $\mathrm{Ob} 5$ were activated by the addition of $\mathrm{Ca}^{2+}$; Ovl and $\mathrm{Ob} 5$ were activated by the addition of $\mathrm{Cr}^{3+}$ and Ov6, Ov7 and Ob5 were activated by the addition of $\mathrm{Se}^{4+}$. Ob5 was the only benign isoenzyme activated. Results for different isoenzymes reacting with the same metal ions and for the same isoenzyme reacting with different metal ions were all significantly different at the $1 \%$ level.

There was no apparent pattern to the effect of different metal ions on the activity of the isoenzymes. No metal activated all the isoenzymes from either the virulent or benign isoenzyme groups and their effects on the activity of isoenzymes in both groups were similar.

Characteristics shared by the proteinase isoenzymes of both benign and virulent strains include their $\mathrm{pH}$ optima, reaction with inhibitors and their molecular weight range. The isoenzymes differed in their thermal stability, $\mathrm{pH}$ stability, reaction to metal ions and their rates of hydrolysis of various proteinaceous substrates; these properties could be worthy of further study as virulence determinants of $B$. nodosus.

I thank T. M. Skerman for providing the cultures. 


\section{REFERENCES}

Beveridge, W. I. B. (1941). Footrot in sheep: a transmissible disease due to infection with Fusiformis nodosus (n. sp.). Bulletin, Council for Scientific and Industrial Research, Australia No. 140, pp. 1-64.

Böhlen, P., Stein, S., Dairman, W. \& Udenfriend, S. (1973). Fluorometic assay of proteins in the nanogram range. Archives of Biochemistry and Biophysics 155, 213-220.

Broad, T. E. \& Skerman, T. M. (1976). Partial purification and properties of extracellular proteolytic activity of Bacteroides nodosus. New Zealand Journal of Agricultural Research 19, 317-322.

Conover, W. J. (1980). Practical Nonparametric Statistics, 2nd edn, pp. 299-305. New York : John Wiley \& Sons.

Depiazzi, L. J. \& Richards, R. B. (1979). A degrading proteinase test to distinguish benign and virulent ovine isolates of Bacteroides nodosus. Australian Veterinary Journal 55, 25-28.

Egerton, J. R. \& LAING, E. A. (1978/1979). Characteristics of Bacteroides nodosus isolated from cattle. Veterinary Microbiology 3, 269-279.

Egerton, J. R. \& Parsonson, I. M. (1969). Benign foot-rot - a specific interdigital dermatitis of sheep associated with infection by less proteolytic strains of Fusiformis nodosus. Australian Veterinary Journal 45, 345-349.

EVERY, D. (1981). Quantitative measurement of protease activities in slab polyacrylamide gel electrophoretograms. Analytical Biochemistry 116, 519 523.

Every, D. (1982). Proteinase isoenzyme patterns of Bacteroides nodosus: distinction between ovine virulent isolates, ovine benign isolates and bovine isolates. Journal of General Microbiology 128, 809 812.

Every, D. \& Green, R. S. (1982). Purification of individual proteinase isozymes from Bacteroides nodosus by use of polyacrylamide gel electrophoresis, a fluorogenic substrate detection system and a simple electroelution apparatus. Analytical Biochemistry 119, 82-85.

GreEN, R. S. (1984). A method to differentiate between virulent and benign isolates of Bacteroides nodosus based on the thermal stability of their extracellular proteinases. New Zealand Veterinary Journal 33, 11-13.

Kortt, A. A., O'Donnell, I. J., Stewart, D. J. \& Clark, B. L. (1982). Activities and partial purifica- tion of extracellular proteases of Bacteroides nodosus from virulent and benign footrot. Australian Journal of Biological Sciences 35, 481-489.

Partridge, S. M., Davis, H. F. \& Adair, G. S. (1955). The chemistry of connective tissues 2. Soluble proteins derived from partial hydrolysis of elastin. Biochemical Journal 61, 11-21.

Piez, K. A., Eigner, E. A. \& Lewis, M. S. (1963). The chromatographic separation and amino acid composition of the subunits of several collagens. Biochemistry 2, 58-66.

Pras, M. \& GlynN, L. E. (1973). Isolation of a noncollagenous reticulin component and its primary characterization. British Journal of Experimental Pathology 54, 449-456.

Richards, R. B., DePiazzi, L. J., Edwards, J. R. \& WILKINSON, F. C. (1980). Isolation and characterisation of Bacteroides nodosus from foot lesions of cattle in Western Australia. Australian Veterinary Journal 56, 517-521.

Rinderknecht, H., Geokas, M. C., Silverman, P. \& HAVERBACK, B. J. (1968). A new ultrasensitive method for the determination of proteolytic activity. Clinica chimica acta 21, 197-203.

Schumacher, G. F. B. \& SCHILl, W.-B. (1972). Radial diffusion in gel for microdetermination of enzymes. II. Plasminogen activator, elastase, and non-specific proteases. Analytical Biochemistry 48, 9-26.

SKERMAN, T. M. (1975). Determination of some in vitro growth requirements of Bacteroides nodosus. Journal of General Microbiology 87, 107-119.

Steinert, P. M., Idler, W. W., Poirier, M. C., Katoh, Y., Stoner, G. D. \& YusPa, S. H. (1979). Subunit structure of the mouse epidermal keratin filament. Biochimica et biophysica acta 577, 11-21.

STEWART, D. J. (1979). The role of elastase in the differentiation of Bacteroides nodosus infections in sheep and cattle. Research in Veterinary Science 27, 99-105.

Thomas, J. H. (1962). The bacteriology and histopathology of footrot in sheep. Australian Journal of Agricultural Research 13, 725-733.

Thomas, J. H. (1963). A liquid medium for the growth of Fusiformis nodosus. Australian Veterinary Journal 39, 434-437.

Thomas, J. H. (1964). The pathogenesis of footrot in sheep with reference to proteases of Fusiformis nodosus. Australian Journal of Agricultural Research 15, 1001-1016. 